\title{
Sulfur Polymer Stabilization/Solidification (SPSS) Treatment of Mixed-Waste Mercury Recovered from Environmental Restoration Activities at BNL
}

\author{
P.D. Kalb, J.W. Adams, and L.W. Milian
}

January 2001

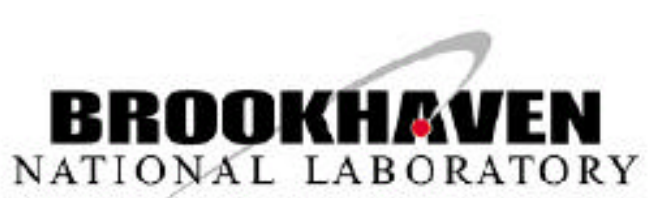

Environmental Sciences Department

Brookhaven National Laboratory

Brookhaven Science Associates

Upton, Long Island, New York 11973

Under Contract No. DE-AC02-98CH10886 with the UNITED STATES DEPARTMENT OF ENERGY 
This report was prepared as an account of the work sponsored by an agency of the United States Government. Neither the United States Government nor any agency thereof, nor any of their employees, nor any of their contractors, subcontractors or their employees, makes any warranty, express or implied, or assumes any legal liability or responsibility for the accuracy, completeness, or any third party's use or the results of such use of any information, apparatus, product, or process disclosed, or represents that its use would not infringe privately owned rights. Reference herein to any specific commercial product, process, or service by trade name, trademark, manufacturer, or otherwise, does not necessarily constitute or imply its endorsement, recommendation, or favoring by the United States Government or any agency thereof, or its contractors or subcontractors. The views and opinions of authors expressed herein do not necessarily state or reflect those of the United States Government or any agency thereof. 


\title{
Sulfur Polymer Stabilization/Solidification (SPSS) Treatment of Mixed-Waste Mercury Recovered from Environmental Restoration Activities at BNL *
}

\author{
P.D. Kalb, J.W. Adams, and L.W. Milian
}

January 2001

\author{
Work Conducted for \\ U.S. Department of Energy \\ Office of Science and Technology \\ Mixed Waste Focus Area
}

Work Conducted by

Environmental Research and Technology Division

Department of Environmental Science

Brookhaven National Laboratory

Upton, NY 11973

* This work was performed under the auspices of the U.S. D epartment of Energy. 



\begin{abstract}
Over $1140 \mathrm{yd}^{3}$ of radioactively contaminated soil containing toxic mercury $(\mathrm{Hg})$ and several liters of mixedwaste elemental mercury were generated during a Comprehensive Environmental Response, Compensation and Liability Act (CERCLA) removal action at Brookhaven National Laboratory (BNL). The U.S. Department of Energy's (DOE) Office of Science and Technology Mixed Waste Focus Area (DOE MWFA) is sponsoring a comparison of several technologies that may be used to treat these wastes and similar wastes at BNL and other sites across the DOE complex. This report describes work conducted at BNL on the application and pilot-scale demonstration of the newly developed Sulfur Polymer Stabilization/Solidification (SPSS) process for treatment of contaminated mixed-waste soils containing high concentrations ( $\sim 5000 \mathrm{mg} / \mathrm{L})$ of mercury and liquid elemental mercury. BNL's SPSS (patent pending) process chemically stabilizes the mercury to reduce vapor pressure and leachability and physically encapsulates the waste in a solid matrix to eliminate dispersion and provide long-term durability. Two 55gallon drums of mixed-waste soil containing high concentrations of mercury and about $62 \mathrm{~kg}$ of radioactively contaminated elemental mercury were successfully treated. Waste loadings of $60 \mathrm{wt} \%$ soil were achieved without resulting in any increase in waste volume, while elemental mercury was solidified at a waste loading of $33 \mathrm{wt} \%$ mercury. Toxicity Characteristic Leaching Procedure (TCLP) analyses indicate the final waste form products pass current Environmental Protection Agency (EPA) allowable TCLP concentrations as well as the more stringent proposed Universal Treatment Standards. Mass balance measurements show that $99.7 \%$ of the mercury treated was successfully retained within the waste form, while only $0.3 \%$ was captured in the off gas system.
\end{abstract}




\section{Table of Contents}

\section{Page}

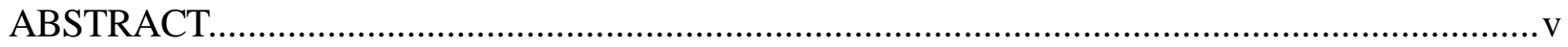

1. INTRODUCTION

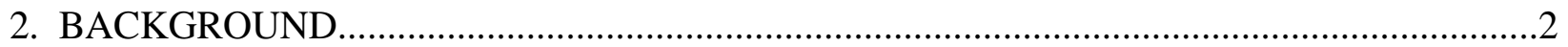

3. TECHNOLOGY DESCRIPTION ……………

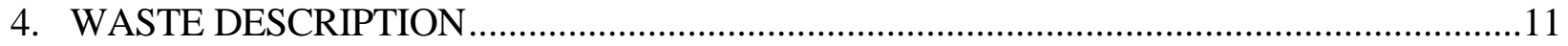

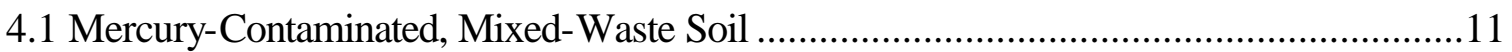

4.2 Liquid Mercury Mixed Waste......................................................................................15

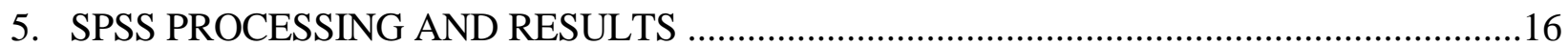

5.1 Mercury-Contaminated, Mixed-Waste Soil ………………………….........................16

5.2 Liquid Mercury Mixed Waste.............................................................................19

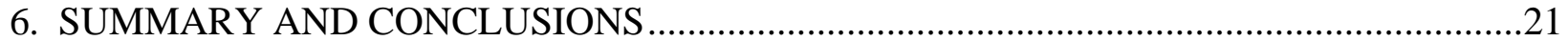

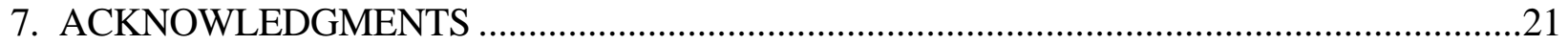

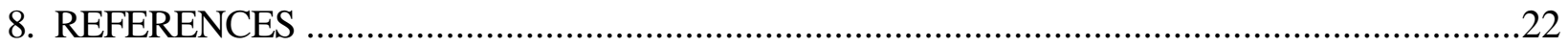




\section{List of Figures}

\section{Page}

Figure 1. Schematic Drawing of Ross Vertical Cone Mixer. ........................................................

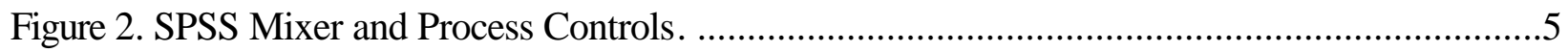

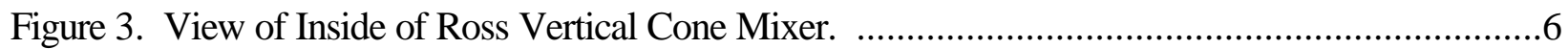

Figure 4. Vertical Cone Mixer Output Valve. …………............................................................

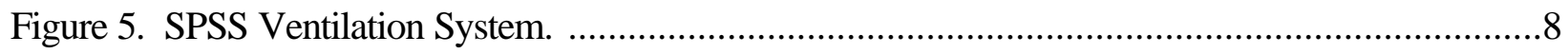

Figure 6. Flowchart Depicting SPSS Off Gas Treatment. ...............................................................

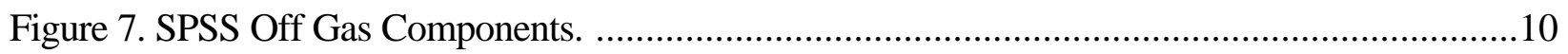

Figure 8. Volumetric Comparison of SPSS Batch Components and

Final Waste Form (right). ...............................................................................................17 


\section{List of Tables}

\section{Page}

Table 1. Characterization Data for B-25 Boxes of Mercury-Contaminated, Mixed-Waste Soils.

Table 2. TCLP Metals Analysis for Four Drums of Soil Taken From B-25 Box 1. .........................13

Table 3. TCLP Metals Analysis for Four Drums of Soil Taken From B-25 Box 2............................14

Table 4. Inventory and Characterization of BNL Mixed-Waste Mercury.........................................15

Table 5. TCLP Results for SPSS Treated Mercury-Contaminated, Mixed-Waste Soils....................18

Table 6. Mass Balance of Condensates for SPSS Treated A4 and E1 Waste Streams....................19

Table 7. TCLP Results for SPSS Treated Elemental Mercury. ...................................................2 


\section{INTRODUCTION}

Sulfur Polymer Stabilization/Solidification, SPSS (patent pending), is a new technology for treatment of elemental mercury wastes. The process is based on Sulfur Polymer Microencapsulation, a patented mixedwaste treatment technology previously developed at Brookhaven National Laboratory (BNL). ${ }^{1}$ In the SPSS process, mercury present in the waste is reacted with powdered sulfur polymer cement (SPC, which consists of $95 \mathrm{wt} \%$ elemental sulfur and $5 \mathrm{wt} \%$ organic modifiers) to form a stable mercury sulfide compound with significantly reduced leachability and lower vapor pressure. The reacted mixture is then melted, mixed, and cooled to form a monolithic solid waste form in which the stabilized mercury particles are microencapsulated within a sulfur polymer matrix. Extensive testing of sulfur polymer waste forms has indicated excellent performance under anticipated disposal conditions. ${ }^{2,3}$ Original development to apply the technology for treatment of elemental mercury was sponsored by the U.S. Department of Energy, Mixed Waste Focus Area (DOE MWFA) as a "Quick Win" project. ${ }^{4}$ During FY97, BNL's Environmental \& Waste Management Group (EWMG) completed bench-scale testing of the SPSS process and successfully applied the technology for treatment of BNL's entire inventory of mixed-waste elemental mercury $(24.5 \mathrm{~kg})$ stored by the BNL Waste Management Division.

The objective of this work was to scale the process up from bench-scale, confirm applicability for treatment of mercury-contaminated soils, and to conduct a pilot-scale technology demonstration using actual soil and elemental mercury wastes. This work was undertaken as part of a technology comparison ("Mercury Bakeoff') to identify potential treatment options for BNL mixed-waste mercury wastes generated during remediation of the BNL Chemical Holes. Results from SPSS will be compared with similar treatability studies for alternative treatment methods, e.g., thermal treatment/vapor recovery (retort), and stabilization to be conducted by other participants in the project.

During excavation of the BNL Chemical Holes, approximately $100 \mathrm{ft}^{3}$ of soil, identified as potentially high in mercury, was removed and placed in two B-25 boxes, each about half full. Preliminary characterization showed $\mathrm{Hg}$ soil concentration to be approximately $6750 \mathrm{mg} / \mathrm{L}$ and $18,000 \mathrm{mg} / \mathrm{L}$ for the two B- $25 \mathrm{~s}$, numbered 1 and 2, respectively. The primary radiological contaminants of concern were found to be Am241 and Eu-152, 154. (Further characterization data are presented in Section 5). In addition to contaminated soils, $62 \mathrm{~kg}$ (approximately $137 \mathrm{lb}$ ) of liquid elemental mercury was also retrieved from the BNL Chemical Holes area. The mercury was either buried and/or collected during remediation in 28 plastic and glass containers of different sizes. The radiological contaminants, although very low in concentration, have been identified as U-235, U-238, Ra-226, Am-241, Eu-152, Cs-137, and Co-60. 


\section{BACKGROUND}

DOE has estimated that $>38,000 \mathrm{~m}^{3}$ of mixed low-level and transuranic wastes contain mercury. These wastes are found at virtually every DOE facility throughout the U.S. Approximately $6 \mathrm{~m}^{3}$ of liquid elemental mercury are currently being stored and additional inventories are expected to be generated at planned treatment facilities such as the Defense Waste Processing Facility at the Savannah River Site and the Advanced Mixed Waste Treatment Facility at the Idaho National Environmental Engineering Laboratory. ${ }^{5}$ In addition, treatment of other mercury wastes (e.g., soil, debris) through incineration (IMERC) and retort (RMERC) will result in additional volumes of elemental mercury requiring stabilization.

Elemental mercury contaminated with radionuclides, i.e., mixed-waste mercury, is a particularly challenging waste stream to treat. Conventional solidification systems such as hydraulic cement are not effective in containing mercury or mercury salts, and higher temperature processes such as incineration or vitrification

volatilize the mercury, requiring secondary treatment of off gases. ${ }^{1}$ The performance requirements (e.g., leachability, vapor pressure) of treated products are stringent. Mercury is a highly toxic metal, so Environmental Protection Agency (EPA) regulations contained in 40 CFR 261 restrict allowable concentrations of leachable mercury to very low levels $(0.2 \mathrm{mg} / \mathrm{L}$, or 200 parts per billion). Newer, more stringent Universal Treatment Standard limits will restrict leachable mercury from non-waste water sources to $0.025 \mathrm{mg} / \mathrm{L}$ ( 25 parts per billion). Occupational Safety and Health Administration (OSHA) regulations restrict worker exposure to mercury vapors to a low Threshold Limit Value (TLV) of $0.05 \mathrm{mg} / \mathrm{m}^{3}$.

For liquid elemental mercury, EPA has identified amalgamation (AMLGM) as the appropriate treatment standard. ${ }^{6}$ This "amalgamation" requires that the mercury be combined with reagents such as copper, gold, or sulfur that result in a solid, non-volatile product. A study by Oak Ridge National Laboratory found mercury stabilization using sulfur to have better leaching properties and lower vapor pressures compared with other reagents. ${ }^{7}$ Although referred to as amalgamation, combining mercury with sulfur results in mercuric sulfide, an ionically bonded compound, not an amalgam or alloy, where stable intermediate compounds are formed as liquid mercury is mixed with a metal in the solid state. Although conventional sulfur treatment produces a chemically stable dry powder, it does not provide any additional barrier to leaching and is susceptible to mechanical dispersion of the radioactive material. These limitations have significant health and safety consequences for the storage, transport, and ultimate disposal of treated mixedwaste mercury.

\section{TECHNOLOGY DESCRIPTION}

Sulfur Polymer Stabilization/Solidification (SPSS) is based on Sulfur Polymer Microencapsulation, a patented, mixed-waste treatment technology previously developed at BNL. ${ }^{8}$ Sulfur Polymer Cement (SPC) consists of $95 \mathrm{wt} \%$ elemental sulfur reacted with $5 \mathrm{wt} \%$ of an organic modifier to enhance mechanical integrity and long-term durability. Previous testing conducted on sulfur polymer waste forms indicates excellent performance under anticipated disposal conditions. ${ }^{9,10}$ 
SPSS mercury treatment is conducted in two stages. The first step is a reaction between mercury and powdered SPC, forming mercuric sulfide, as seen in Equation 1:

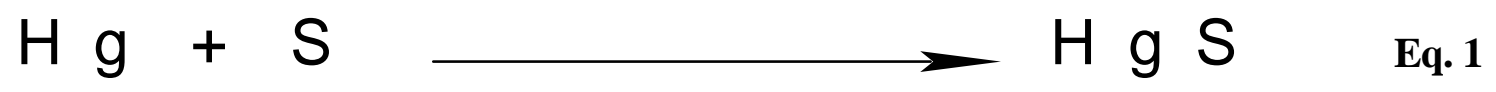

Since the BNL SPSS process includes chemical stabilization of the mercury yielding mercury sulfide, it meets EPA requirements for AMLGM. For treatment of elemental $\mathrm{Hg}$, equal masses of mercury and SPC are mixed in the reaction vessel, assuring nearly a six-fold molar excess of sulfur to mercury and facilitating a faster reaction of the mercury metal with sulfur. For $\mathrm{Hg}$ contaminated soil, waste loading is determined based on mixability constraints as well as the concentration of $\mathrm{Hg}$ in the waste. Prior to mixing, the reaction vessel is placed under inert gas atmosphere to prevent the formation of mercuric oxide (a water soluble and highly leachable compound) and a small quantity of additive is included to accelerate the reaction. The vessel is heated to $\sim 40^{\circ} \mathrm{C}$ during the stabilization phase to accelerate the sulfide formation reaction and the materials are mixed until the mercury is completely reacted with the sulfur. Once the mercury is chemically stabilized, additional SPC is added and the mixture is heated at about $130^{\circ} \mathrm{C}$ until a homogeneous molten mixture is formed. It is then poured into a suitable mold where it cools to form a monolithic solid waste form.

SPSS processing was accomplished using a $1 \mathrm{ft}^{3}$ pilot-scale vertical cone blender/dryer (Ross Mixers, Hauppauge, NY). Mixing action is provided by an orbital, helical screw, which rotates like an auger (105 $\mathrm{rpm})$ as it revolves orbitally around the wall of the vessel $(2.5 \mathrm{rpm})$, drawing material upward from the base of the cone. Feed materials are charged to the unit through a 6-inch diameter port on the cone lid. A schematic drawing and photographs of the mixer are shown in Figures 1 through 3 . When mixing or drying, the system may be operated under vacuum through the use of a 14.6-cfm, 0.5-hp vacuum pump, or under inert atmosphere, by connection to a regulated nitrogen gas supply. Heat is provided to the jacketed cone by a $9 \mathrm{~kW}$ circulating fluid heat transfer system (Mokon, Buffalo, NY). A $5 \mathrm{~cm}$ ( 2 in) heated ball valve at the base of the cone was used to discharge the molten SPSS product (Figure 4). A HEPA filtered ventilation system (Figure 5), featuring a $25 \mathrm{~cm}$ (10 in) diameter ventilation line and 1000-cfm blower, was used to prevent dispersion of particles during charging.

Off gas is captured in multiple stages: first it passes through a shell and tube heat exchanger cooled by a 3 ton chiller (Mokon), followed by a liquid nitrogen cryogenic trap and finally through HEPA and activated charcoal filters before venting to the atmosphere. Condensate is collected at the heat exchanger in an offgas condensate vessel and at the cryogenic trap, for analyses. A process flowchart and photograph of the off-gas system components are shown in Figures 6 and 7, respectively. 


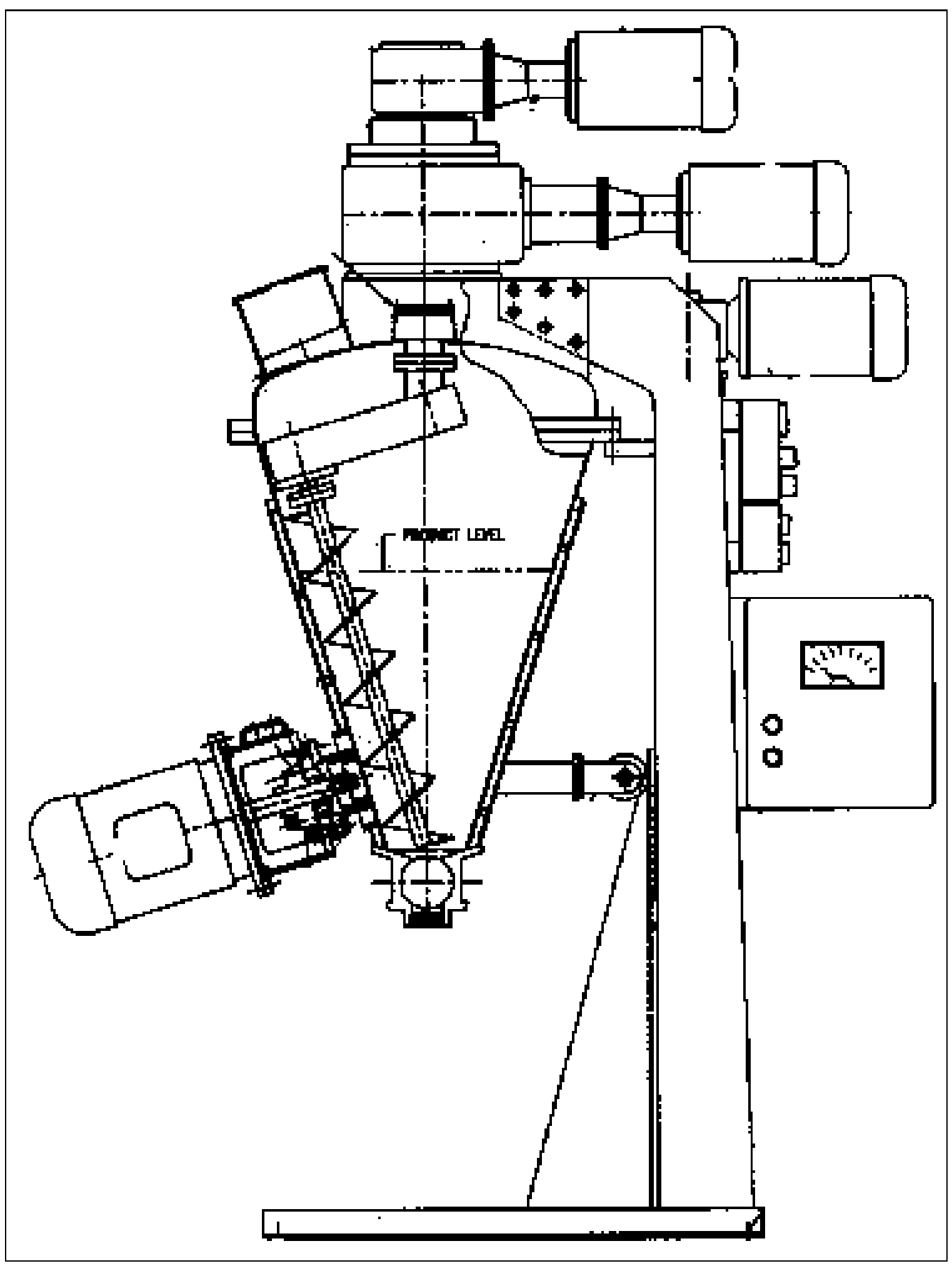


Figure 1. Schematic drawing of Ross vertical cone mixer. 


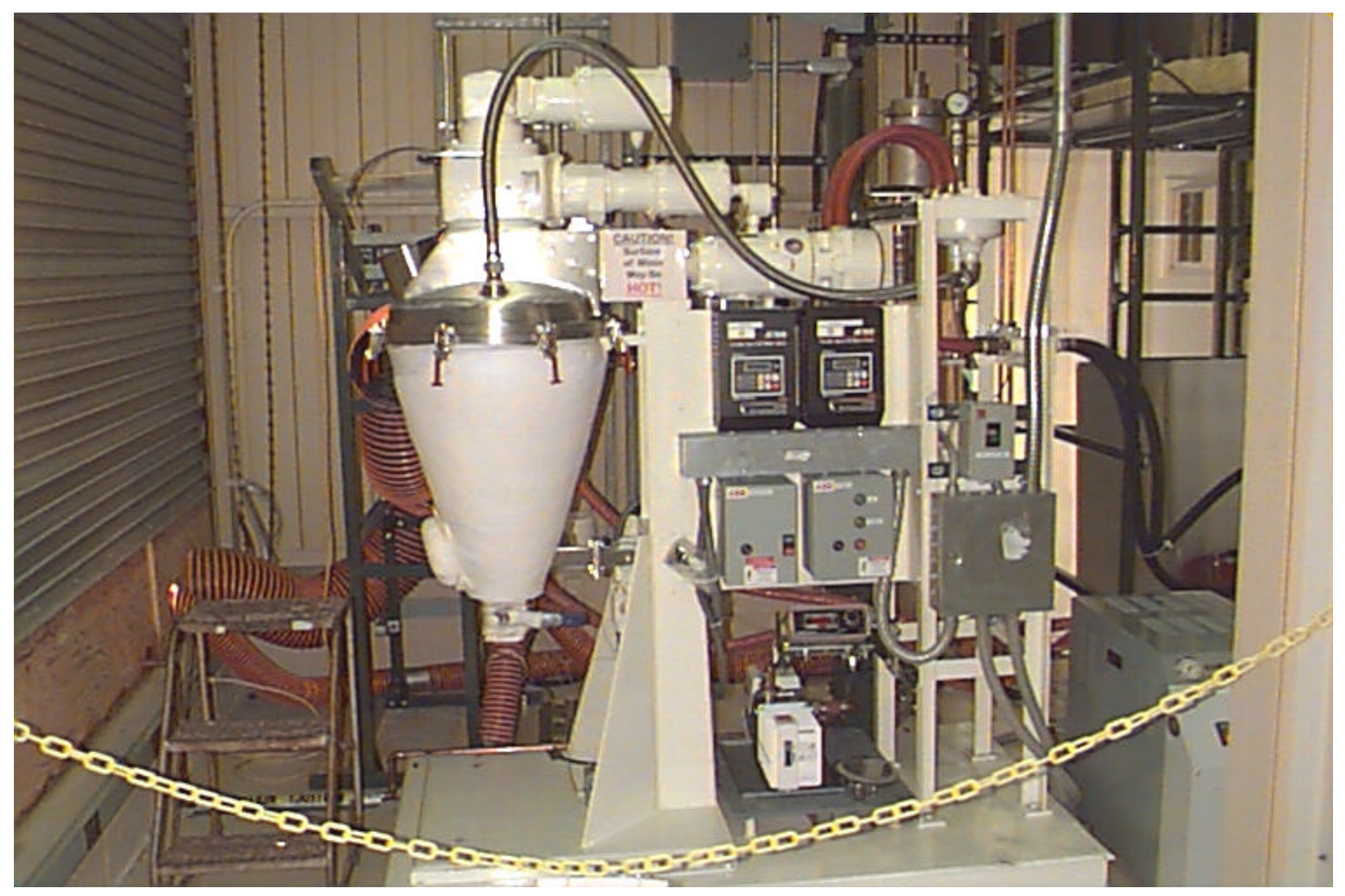




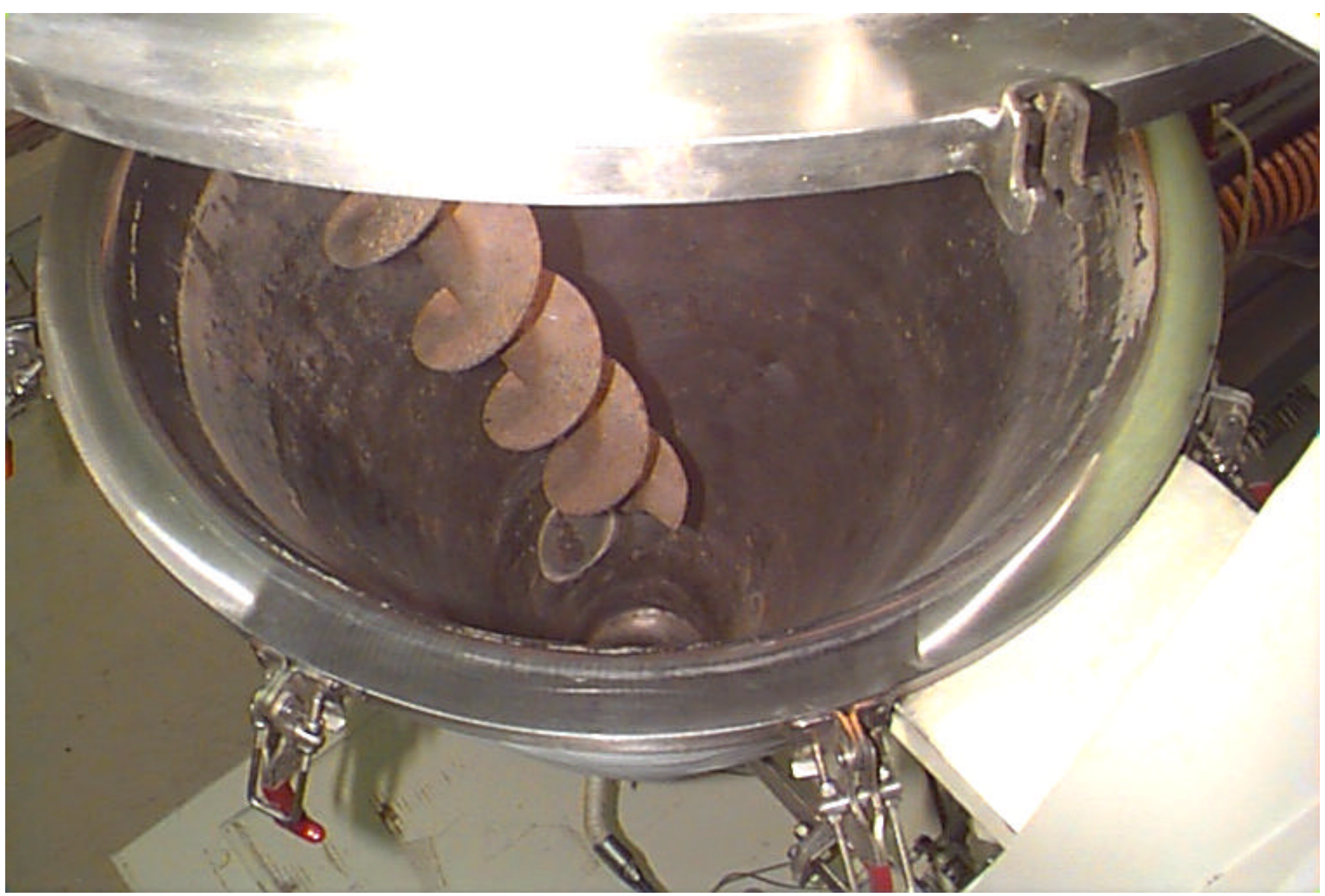

Figure 3. View of inside of Ross vertical cone mixer. 


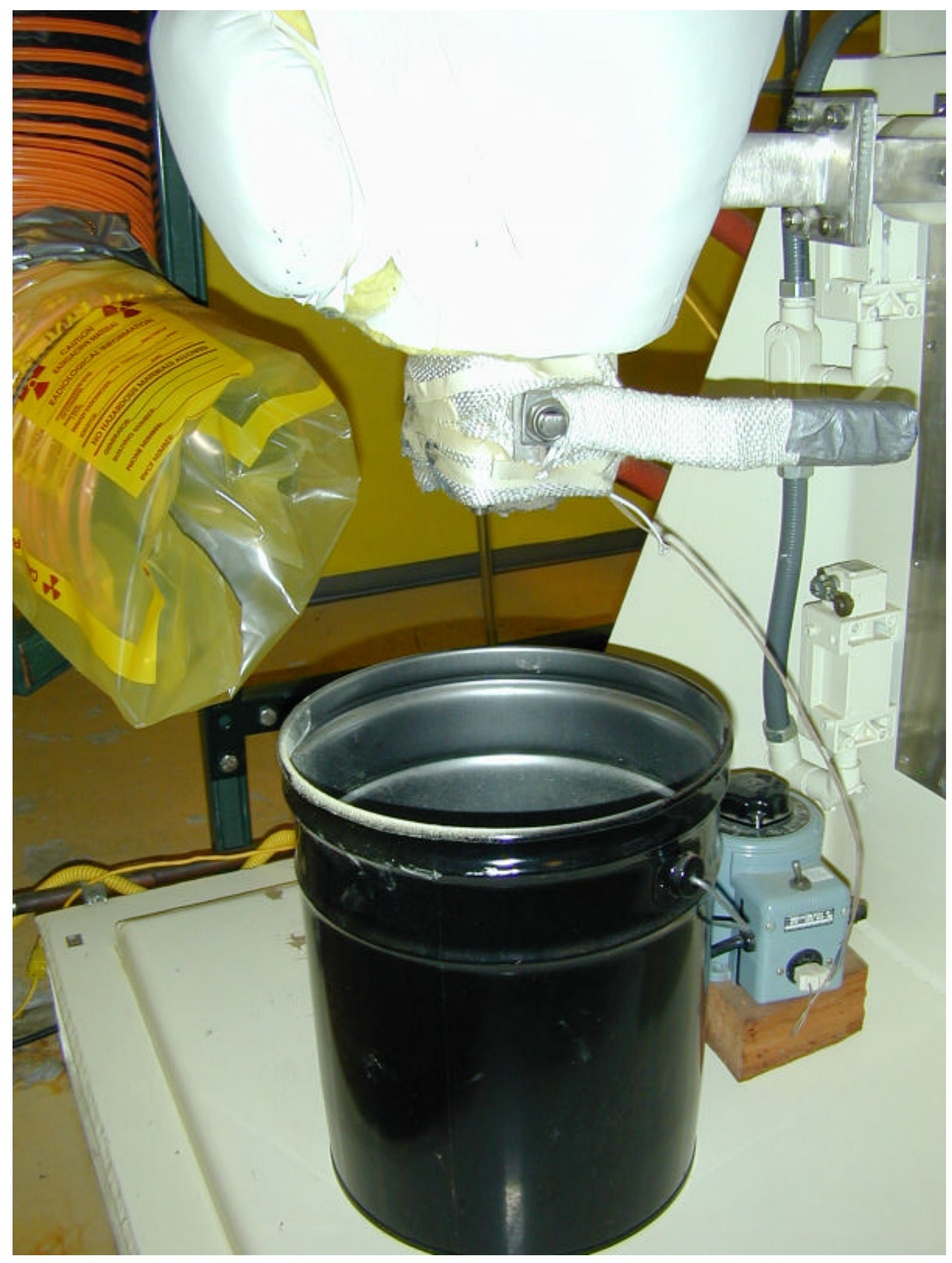





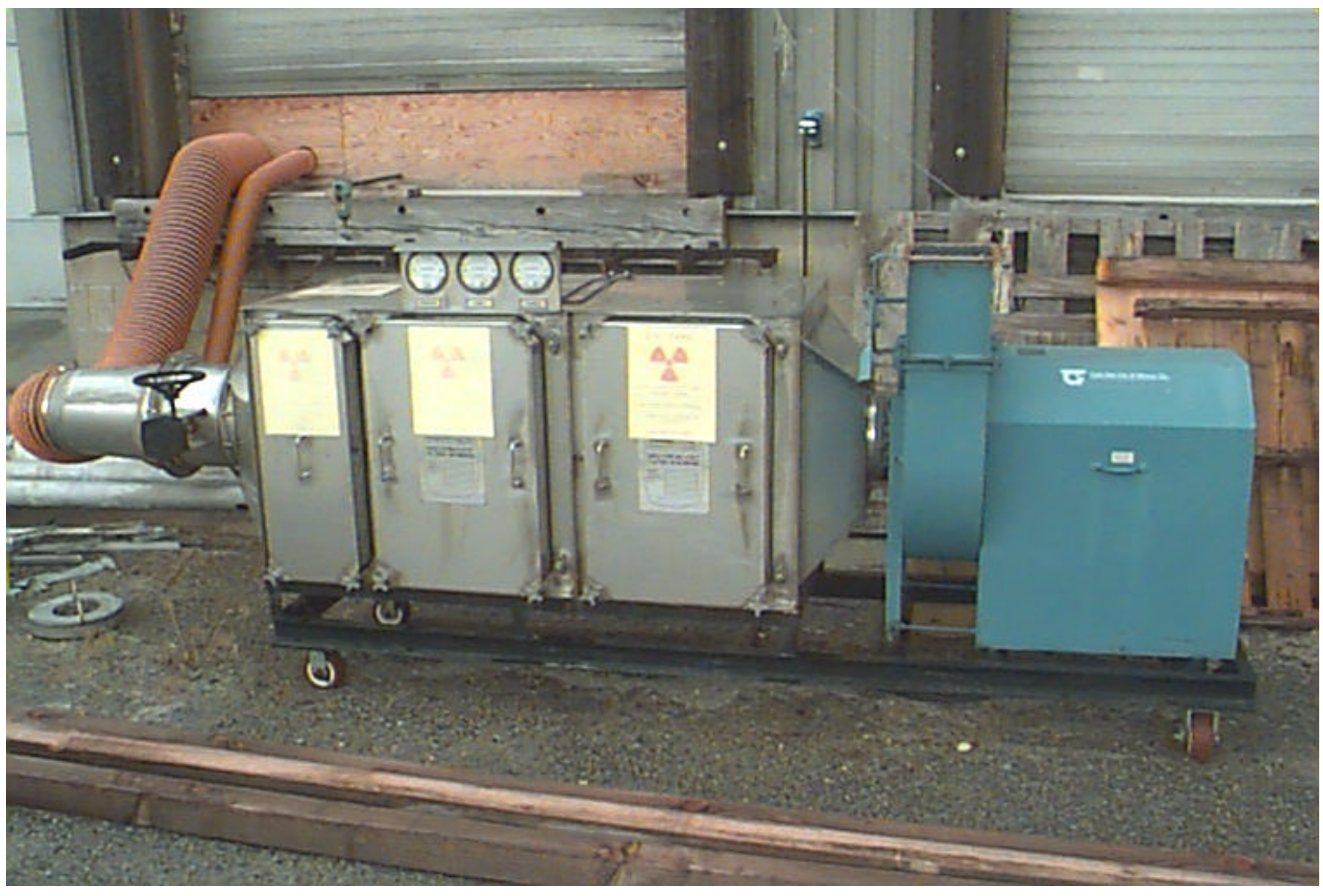

Figure 5. SPSS ventilation system. 


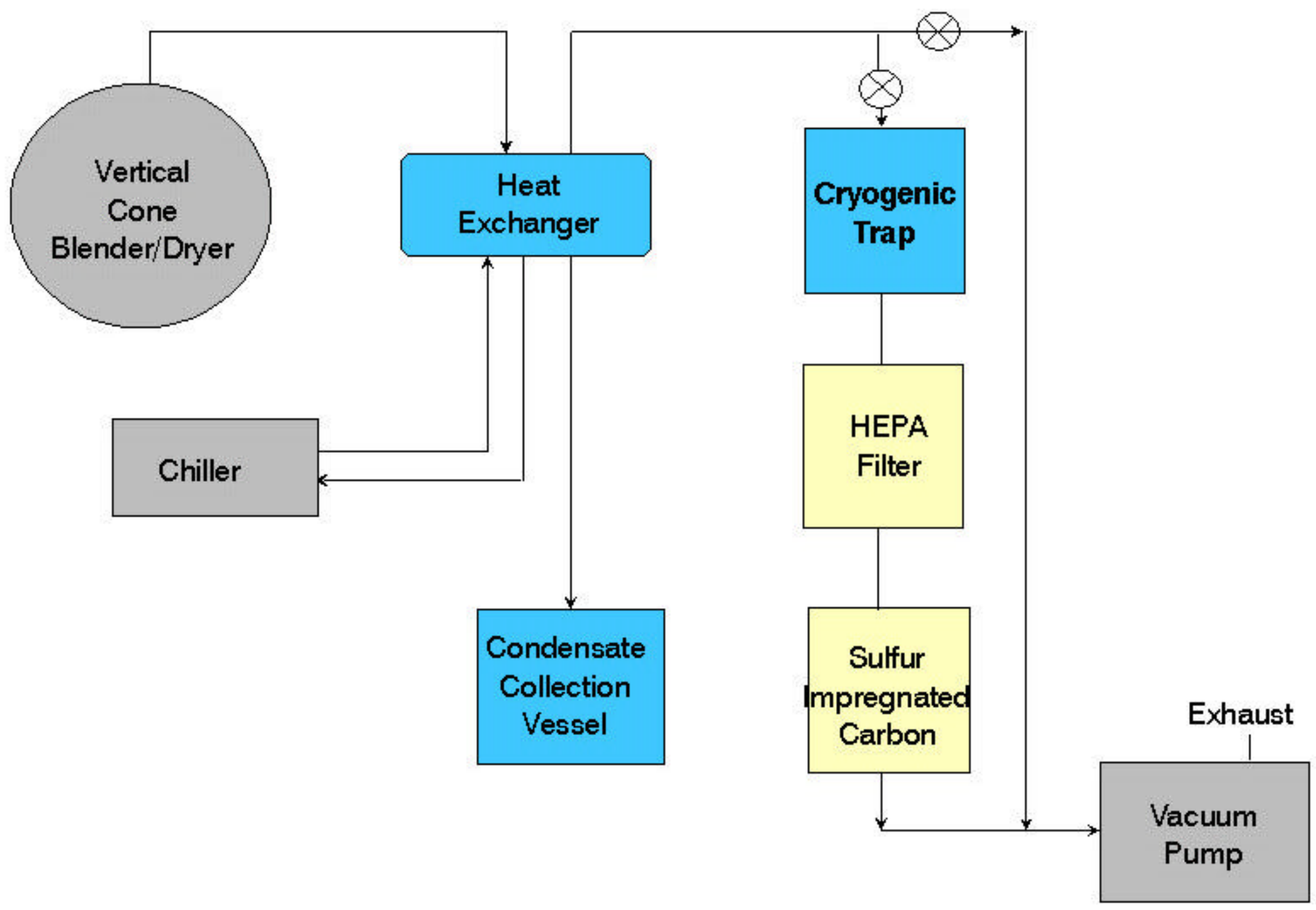


Figure 6. Flowchart depicting SPSS off-gas treatment. 



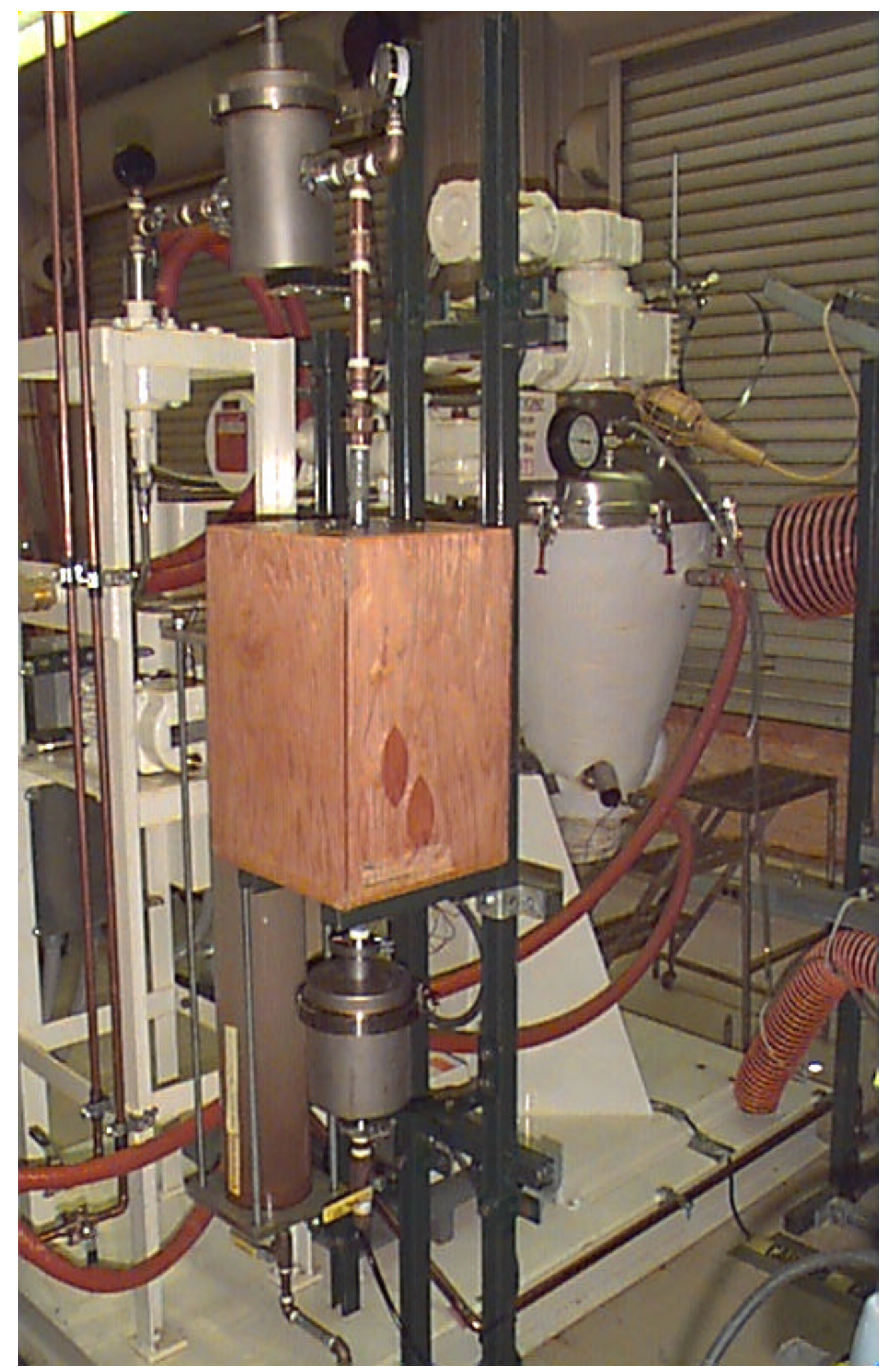

Figure 7. SPSS off-gas components. 


\section{WASTE DESCRIPTION}

Mixed waste streams targeted by this work were legacy wastes encountered at the BNL site. The BNL Environmental Restoration Division (ERD) in compliance with CERCLA and New York State regulations conducted a remedial excavation of the Animal/Chemical Pits and Glass Holes in the summer of 1997. The site consisted, in part, of radioactive animal carcasses along with glass bottles containing elemental mercury, some of which had broken on placement or retrieval. Following removal of wastes, debris, and contaminated soil from a total of 55 separate waste pits, the materials were sorted, segregated, characterized, and either securely stored on-site or shipped for off-site disposal. One pile of approximately $440-\mathrm{yd}^{3}$ of soil (Stockpile 6B) was identified as mixed waste, since composite samples failed TCLP for mercury. Another pile of about $700-\mathrm{yd}^{3}$ of soil (Stockpile 12) contained visible concentrations of mercury but passed initial TCLP tests. A smaller volume of approximately $100 \mathrm{ft}^{3}$ was segregated into two partially filled B-25 boxes because it contained higher concentrations, i.e., >260 mg/L of mercury. The $260 \mathrm{mg} / \mathrm{L}$ mercury concentration criterion is based on current EPA Land Disposal Restriction (LDR) treatment standards. For wastes containing $<260 \mathrm{mg} / \mathrm{L}$ mercury, the EPA specific treatment standard is stabilization. Above $260 \mathrm{mg} / \mathrm{L}$ mercury, the EPA specific treatment standard is RMERC (retorting or roasting with recovery of the mercury for reuse). However, in the case of mixed-waste mercury-contaminated soils, separation of the mercury results in two waste streams requiring additional treatment/disposal, i.e., mixedwaste mercury residuals and radioactive soils. Thus, for this project, BNL requested and received from EPA, a Determination of Equivalent Treatment (DET). The DET allows direct treatment (SPSS) of the mixed-waste soils containing >260 mg/L, as long as compliance with Land Disposal Regulations (LDR), i.e., TCLP standards for stabilized $\mathrm{Hg}$ is demonstrated. In a recent Notice of Proposed Rule Change, EPA is examining possible revisions to 40 CFR 266 to allow direct stabilization of mixed wastes contaminated with $>260$ mg/L mercury. ${ }^{11}$

\subsection{Mercury-Contaminated, Mixed-Waste Soil}

The soil waste used for this project consisted of approximately $4990 \mathrm{~kg}$ of radioactively contaminated soil, originally contained in two B-25 boxes. The physical composition of the soil was mostly sand and silt with a small percentage of gravel and approximately 5\% debris (glass, metal and plastic), most of which was removed during subsequent repackaging operations. During excavation, the soil was screened to less than 1 inch. Significant homogenization of the soil in the B-25 boxes occurred during the segregation/screening process. Composite characterization data, summarized in Table 1, indicate average total mercury concentrations of $6750 \mathrm{mg} / \mathrm{kg}$ and 18,000 mg/kg in the two containers. Representative samples of each waste bin were TCLP tested, yielding mercury concentrations of $3.56 \mathrm{mg} / \mathrm{L}$ and $0.26 \mathrm{mg} / \mathrm{L}$, respectively (above current limits of $0.2 \mathrm{mg} / \mathrm{L}$ ), making them subject to LDR treatment standards. In addition to varying levels of mercury, the two drums differed in isotopic mixture and concentrations. One contained relatively high concentrations of Am-241 and the other primarily Eu-152 and Ra-226.

Each B-25 box of soil was subdivided into seven 55-gallon drums for eventual distribution to project participants. To ensure testing of comparable wastes, the soil was evenly divided when repackaged by 
manually shoveling small scoops into each drum in turn. Large pieces of debris were manually removed while repackaging. The drums were assigned a unique identification number (A1 - A7, for the drums containing americium, and E1 - E7, for the drums containing europium) and sealed to ensure chain of custody. Composite samples taken from each drum were analyzed to confirm equivalent source term composition of the waste. Full TCLP metals analysis of samples from drums A1-A4 and E1-E4 were performed; results are shown in Tables 2 and 3, respectively. Total mercury measurements of the soils ranged from 2310 to $5570 \mathrm{mg} / \mathrm{kg}$, with an average of just over $4000 \mathrm{mg} / \mathrm{kg}$.

Table 1. Characterization Data for B-25 Boxes of Mercury-Contaminated, Mixed-Waste Soils.

\begin{tabular}{|l|l|l|}
\hline Parameter & B-25 Box 1 & B-25 Box 2 \\
\hline Hg (total) & $6750 \mathrm{mg} / \mathrm{kg}$ & $18,000 \mathrm{mg} / \mathrm{kg}$ \\
\hline $\mathrm{Hg}(\mathrm{TCLP})$ & $3.56 \mathrm{mg} / \mathrm{L}$ & $0.263 \mathrm{mg} / \mathrm{L}$ \\
\hline Gross Alpha & $4560 \mathrm{pCi} / \mathrm{g}$ & $24.9 \mathrm{pCi} / \mathrm{g}$ \\
\hline Gross Beta & $525 \mathrm{pCi} / \mathrm{g}$ & $35.9 \mathrm{pCi} / \mathrm{g}$ \\
\hline $\mathrm{Am}^{241}$ & $7140 \mathrm{pCi} / \mathrm{g}$ & - \\
\hline $\mathrm{Pu}^{238}$ & $72.6 \mathrm{pCi} / \mathrm{g}$ & - \\
\hline $\mathrm{Pu}^{239 / 240}$ & $19.7 \mathrm{pCi} / \mathrm{g}$ & - \\
\hline $\mathrm{Sr}^{90}$ & $2.15 \mathrm{pCi} / \mathrm{g}$ & --- \\
\hline $\mathrm{U}^{233 / 234}$ & --- & $7.06 \mathrm{pCi} / \mathrm{g}$ \\
\hline $\mathrm{U}^{238}$ & --- & $5.87 \mathrm{pCi} / \mathrm{g}$ \\
\hline $\mathrm{Eu}^{152 / 154}$ & --- & $28.7 \mathrm{pCi} / \mathrm{g}$ \\
\hline $\mathrm{Ra}^{226}$ & --- & $35.5 \mathrm{pCi} / \mathrm{g}$ \\
\hline
\end{tabular}

Drums E1 and A4, with net weights of $127 \mathrm{~kg}$ (280 lbs) and $204 \mathrm{~kg}$ (450 lb), respectively, were arbitrarily designated by BNL ERD for SPSS processing. The drums were opened and sampled in a fully contained, HEPA-filtered hot cell. Air monitoring samples from these activities produced Am-241 levels of $2.3 \times 10^{-02}$ $\mu \mathrm{Ci} / \mathrm{g}$. Based on these results, the decision was made to transfer the soils into 1-gallon containers to facilitate loading of the waste into the mixer. To remove large aggregate that could potentially interfere with mixer operation, the as-received soil was sieved to $<9.5 \mathrm{~mm}(3 / 8 \mathrm{in})$ during transfer to smaller buckets. Gravel and small debris retrieved from each drum during sieving amounted to $14.6 \mathrm{~kg}$ for drum E1 and 10.9 $\mathrm{kg}$ for drum A4. Average moisture content of drum E1 was approximately $7.6 \mathrm{wt} \%$, with little variation from top to bottom. Drum A4, was much wetter at the bottom (up to $14 \mathrm{wt} \%$ moisture) compared to the top ( $7 \mathrm{wt} \%$ moisture), with an average moisture content of $8.4 \mathrm{wt} \%$. Soil from the bottom third of drum 
A4 was air dried to reduce moisture content to less than $2 \mathrm{wt} \%$ prior to SPSS processing. 
Table 2. TCLP Metals Analysis for Four Drums of Soil Taken From B-25 Box 1.

\begin{tabular}{|c|c|c|c|c|c|c|c|c|c|}
\hline & & B25-1 $\mathrm{A}^{1}$ & $\overline{\mathrm{A} 1^{2}}$ & $\mathrm{~A} 2^{2}$ & $\mathrm{~A}^{2}{ }^{2}$ & $\overline{\mathrm{A} 4^{2}}$ & Avg. A & $\begin{array}{c}\text { Max } \\
\text { Allowable, } \\
\text { TCLP }\end{array}$ & $\begin{array}{c}\text { Max } \\
\text { Allowable, } \\
\text { UTS }\end{array}$ \\
\hline \multicolumn{2}{|c|}{ Total Hg (mg/kg) } & 6750 & 4040 & 4190 & 2310 & 5570 & 4028 & & \\
\hline \multirow{8}{*}{$\begin{array}{l}\text { TCLP } \\
(\mu \mathrm{g} / \mathrm{L})\end{array}$} & As & $<14.9$ & 40.0 & 40.0 & 40.0 & 40.0 & 40.0 & 5000 & 5000 \\
\hline & $\mathrm{Ba}$ & 162 & 134 & 193 & 357 & 150 & 208 & 100,000 & 21,000 \\
\hline & $\mathrm{Cd}$ & $<1.04$ & 11.4 & 11.4 & 11.4 & 11.4 & 11.4 & 1000 & 110 \\
\hline & $\mathrm{Cr}$ & $<3.65$ & 7.0 & 7.0 & 7.0 & 7.0 & 7.0 & 5000 & 600 \\
\hline & $\mathrm{Pb}$ & $<3.39$ & 15.0 & 21.6 & 26.3 & 15.0 & 19.5 & 5000 & 750 \\
\hline & $\mathrm{Hg}$ & 3560 & 868 & 1500 & 1390 & $1000^{3}$ & 1190 & 200 & 25 \\
\hline & $\mathrm{Se}$ & $<7.00$ & 24.1 & 24.1 & 24.1 & 24.1 & 24.1 & 1000 & 5700 \\
\hline & $\overline{\mathrm{Ag}}$ & 7.66 & 20.1 & 20.1 & 20.1 & 20.1 & 20.1 & 5000 & 140 \\
\hline
\end{tabular}

${ }^{1}$ Sample D ate 10/9/97; A nalyses by Environmental Physics Inc., Charleston, SC

2 Sample D ate 7/9/98; A nalyses by General Engineering Laboratories, Charleston, SC

${ }^{3}$ Sample Re-tested at BNL on 12/1/98; H g concentration $=914 \mu \mathrm{g} / \mathrm{L}$. 
Table 3. TCLP Metals Analysis for Four Drums of Soil Taken From B-25 Box 2.

\begin{tabular}{|c|c|c|c|c|c|c|c|c|c|}
\hline & & $\overline{\mathrm{B} 25-1 \mathrm{E}^{4}}$ & $\bar{E} \mathrm{E}^{5}$ & $\bar{E} 2^{2}$ & $\bar{E} \mathrm{E}^{2}$ & $\overline{\mathrm{E} 4^{2}}$ & Avg. E & $\begin{array}{c}\text { Max } \\
\text { Allowable, } \\
\text { TCLP } \\
\end{array}$ & $\begin{array}{c}\text { Max } \\
\text { Allowable, } \\
\text { UTS }\end{array}$ \\
\hline \multicolumn{2}{|c|}{ Total $\mathrm{Hg}(\mathrm{mg} / \mathrm{kg})$} & 18,000 & 4190 & 3100 & 4880 & 5510 & 4420 & & \\
\hline \multirow{6}{*}{$\begin{array}{l}\text { TCLP } \\
(\mu \mathrm{g} / \mathrm{L})\end{array}$} & As & $<14.9$ & 40.0 & 40.0 & 40.0 & 40.0 & 40.0 & 5000 & 5000 \\
\hline & $\mathrm{Ba}$ & 219 & 1560 & 1780 & 1480 & 1820 & 1660 & 100,000 & 21,000 \\
\hline & $\mathrm{Cd}$ & 52.8 & 164 & 116 & 99.9 & 148 & 132 & 1000 & 110 \\
\hline & $\mathrm{Cr}$ & 9.10 & 7.0 & 8.9 & 7.0 & 9.2 & 8.0 & 5000 & 600 \\
\hline & $\mathrm{Pb}$ & 79.7 & 754 & 789 & 736 & 993 & 818 & 5000 & 750 \\
\hline & $\mathrm{Hg}$ & 263 & 208 & 246 & 191 & 212 & 214 & 200 & 25 \\
\hline
\end{tabular}

${ }^{4}$ Sample D ate 10/9/97; A nalyses by Environmental Physics Inc., C harleston, SC

${ }^{5}$ Sample Date 7/9/98; A nalyses by General Engineering Laboratories, Charleston, SC 


\begin{tabular}{|c|c|c|c|c|c|c|c|c|}
\hline $\mathrm{Se}$ & $<7.00$ & 24.1 & 24.1 & 24.1 & 24.1 & 24.1 & 1000 & 5700 \\
\hline $\mathrm{Ag}$ & 6.56 & 20.1 & 20.1 & 20.1 & 20.1 & 20.1 & 5000 & 140 \\
\hline
\end{tabular}




\subsection{Liquid Mercury Mixed Waste}

In addition to mixed-waste soils, mixed-waste elemental mercury from the BNL Chemical Holes was also targeted for SPSS processing. This work was conducted with co-funding from the BNL Environmental Restoration Division (EM-40). A total of about $62 \mathrm{~kg}$ (137 lb) of liquid mercury waste was received for treatment. The inventory consisted of 28 individual containers (glass/plastic) of varying quantity/purity. Approximately a quarter of the inventory was positively identified to be radioactive after surveys indicated measurable activity, but all of the waste was treated as mixed waste, based on process knowledge.

Table 4. Inventory and Characterization of BNL Mixed-Waste Mercury.

\begin{tabular}{|c|c|c|c|c|c|}
\hline Container \# & ID & Glass/Plastic & Date & Radionuclide & Mass (kg) \\
\hline 1 & $\mathrm{Ba}-2$ & $\mathrm{P}$ & None & Not Identified & 0.171 \\
\hline 2 & Ba-3 & $\mathrm{P}$ & $4 / 14 / 98$ & Not Identified & 0.685 \\
\hline 3 & $\mathrm{Hg}-5$ & $\mathrm{P}$ & $4 / 14 / 98$ & Not Identified & 2.970 \\
\hline 4 & $\mathrm{Hg}-17$ & $\mathrm{G}$ & $4 / 20 / 98$ & Not Identified & 0.708 \\
\hline 5 & $\mathrm{Hg}-18$ & $\mathrm{P}$ & $4 / 20 / 98$ & Not Identified & 1.308 \\
\hline 6 & $\mathrm{Hg}-16$ & $\mathrm{G}$ & $4 / 20 / 98$ & Not Identified & 1.071 \\
\hline 7 & Hg-19 & $\mathrm{G}$ & $4 / 20 / 98$ & Not Identified & 2.777 \\
\hline 8 & $\mathrm{Hg}-9$ & $\mathrm{P}$ & $4 / 17 / 98$ & Not Identified & 3.171 \\
\hline 9 & $\mathrm{Hg}-15$ & $\mathrm{G}$ & $4 / 20 / 98$ & Not Identified & 4.478 \\
\hline 10 & $\mathrm{Hg}-3$ & $\mathrm{P}$ & $4 / 14 / 98$ & Not Identified & 1.890 \\
\hline 11 & $\mathrm{Hg}-8$ & $\mathrm{G}$ & $4 / 15 / 98$ & Not Identified & 4.486 \\
\hline 12 & $\mathrm{Hg}-25$ & $\mathrm{G}$ & $4 / 22 / 98$ & Not Identified & 1.667 \\
\hline 13 & $\mathrm{Hg}-24$ & $\mathrm{G}$ & $4 / 22 / 98$ & Not Identified & 4.861 \\
\hline 14 & $\mathrm{Hg}-22$ & $\mathrm{G}$ & $4 / 21 / 98$ & Not Identified & 0.223 \\
\hline 15 & $\mathrm{Hg}-21$ & $\mathrm{P}$ & $4 / 21 / 98$ & Not Identified & 3.262 \\
\hline 16 & Hg-20 & $\mathrm{G}$ & $4 / 21 / 98$ & Not Identified & 0.219 \\
\hline 17 & $\mathrm{Hg}-10$ to 14 & G\&P & $4 / 20 / 98$ & Not Identified & 2.040 \\
\hline 18 & $\mathrm{Hg}-4$ & $\mathrm{G}$ & $4 / 14 / 98$ & Not Identified & 6.157 \\
\hline 19 & $\mathrm{Hg}-7$ & $\mathrm{G}$ & $4 / 15 / 98$ & Not Identified & 5.431 \\
\hline \multicolumn{5}{|c|}{ Subtotal non-rad } & 47.575 \\
\hline 20 & $\mathrm{R}-1$ & $\mathrm{P}$ & None & Not Identified & 0.362 \\
\hline 21 & $\mathrm{R}-2$ & $\mathrm{P}$ & $4 / 15 / 98$ & U-235,U-238 & 1.330 \\
\hline 22 & Ba-1 & $\mathrm{P}$ & $5 / 5 / 98$ & Ra-226 & 0.314 \\
\hline 23 & $\mathrm{R}-3$ & $\mathrm{G}$ & $6 / 21 / 98$ & Not Identified & 0.006 \\
\hline 24 & $\mathrm{Ba}-4$ & $\mathrm{P}$ & $5 / 5 / 98$ & $\begin{array}{c}\text { Am-241,Cs- } \\
137, \text { Co-60 } \\
\end{array}$ & 0.541 \\
\hline 25 & $\mathrm{Hg}-2$ & $\mathrm{P}$ & $4 / 13 / 98$ & $\mathrm{U}-235, \mathrm{U}-238$ & 4.408 \\
\hline 26 & $\mathrm{M}-1$ & $\mathrm{G}$ & None & Not Identified & 0.000 \\
\hline 27 & $\mathrm{Hg}-1$ & $\mathrm{P}$ & $4 / 13 / 98$ & $\mathrm{U}-235, \mathrm{U}-238$ & 5.626 \\
\hline 28 & $\mathrm{Hg}-23$ & $\mathrm{G}$ & $4 / 22 / 98$ & U-235,U-238 & 2.153 \\
\hline \multicolumn{5}{|l|}{ Subtotal rad } & 14.741 \\
\hline
\end{tabular}




\section{SPSS PROCESSING AND RESULTS}

Bench-scale development work for the SPSS process demonstrated that as much as $33 \mathrm{wt} \%$ elemental mercury could be successfully encapsulated and still meets EPA TCLP leaching criteria, ${ }^{7}$ so this formulation was used to treat liquid mercury waste from the Chemical and Animal Holes. Although the soils tested in this study contained relatively high concentrations of mercury (up to about 5,000 mg/L), they contained far less mercury on a mass basis than the liquid mercury previously tested. Thus, physical processing parameters (e.g., viscosity of the mix), rather than mercury leachability, represented the limiting constraints on waste processing for mercury-contaminated soils.

\subsection{Mercury-Contaminated, Mixed-Waste Soil}

Using the vertical cone blender, trial process runs were first conducted to determine optimum waste loading (mass of soil to mass of powdered SPC) based on dry mixing, melting, and discharging of the molten mixture. When processing soil waste loadings of $70 \mathrm{wt} \%$, a layer of material tended to stick to the walls of the vessel during discharge, requiring manual scraping. When the waste loading was reduced to $60 \mathrm{wt} \%$ soil, the melt viscosity was lower, and most of the mixture flowed easily out of the vessel into the collection container. For the $60 \mathrm{wt} \%$ mixture, batch size was limited to $41 \mathrm{~kg}(90 \mathrm{lb})$. As the mixing action tended to pull material high up the wall of the vessel, larger batch sizes tended to accumulate a ring of material on the wall that could not be incorporated into the melt. Both of these limitations are related to the design of the mixing vessel and might be improved with modifications to the mixer or selection of an alternate processing system.

Procedure for adding, mixing, and melting components in the cone blender was standardized to yield reproducible batch results. To "lubricate" the walls of the mixer and enhance discharge of material, powdered SPC was added first, followed by as-received soil, such that an SPC-rich layer would be created at the vessel wall. Next, the vessel was evacuated and purged with nitrogen gas. A slight overpressure of nitrogen gas, up to $5 \mathrm{psi}$, was maintained during mixing. The soil/SPC mixture was then reacted for a minimum of 4 hours at $40 \pm 5^{\circ} \mathrm{C}$, to ensure sufficient reaction between the mercury and sulfur. (For early process runs, samples were taken intermittently to determine reaction kinetics.)

Following mixing, the system was evacuated $\left(\$ 26^{\prime \prime} \mathrm{Hg}\right.$ ) and the vessel temperature was increased to $100^{\circ} \mathrm{C}$ to drive moisture off the soil. Complete dryness, which usually occurred in less than 1 hour, was indicated by visible dust in the vessel, followed by a rapid temperature rise of the mixture to the vessel setpoint. Following drying, remaining SPC required by the formulation (as SPC chips) was added to the vessel and the temperature was increased to $135 \pm 5^{\circ} \mathrm{C}$ to melt the SPC and encapsulate the chemically stabilized mercury waste. Melting occurred within 30 minutes, after which time the molten mixture was mixed another 15 minutes prior to discharge into a metal 5-gallon container. While still molten, approximately $500 \mathrm{ml}$ of material was ladled into a glass jar for subsequent analyses. Volume of the SPSS treated waste, which nearly filled the 5-gallon container, was virtually the same as the untreated waste. In the liquid state, the amount of SPC used for encapsulation is that volume required to fill interstitial void space in the soil, thus, no 
volume increase is observed. The lack of volume increase is depicted in Figure 8, which is a photograph of a simulated batch of soil, the reagents required for processing, and the stabilized/solidified waste form. Note that the final waste form volume (5-gallon container on the right) is nearly identical to the volume of the untreated waste (5-gallon container on the left).

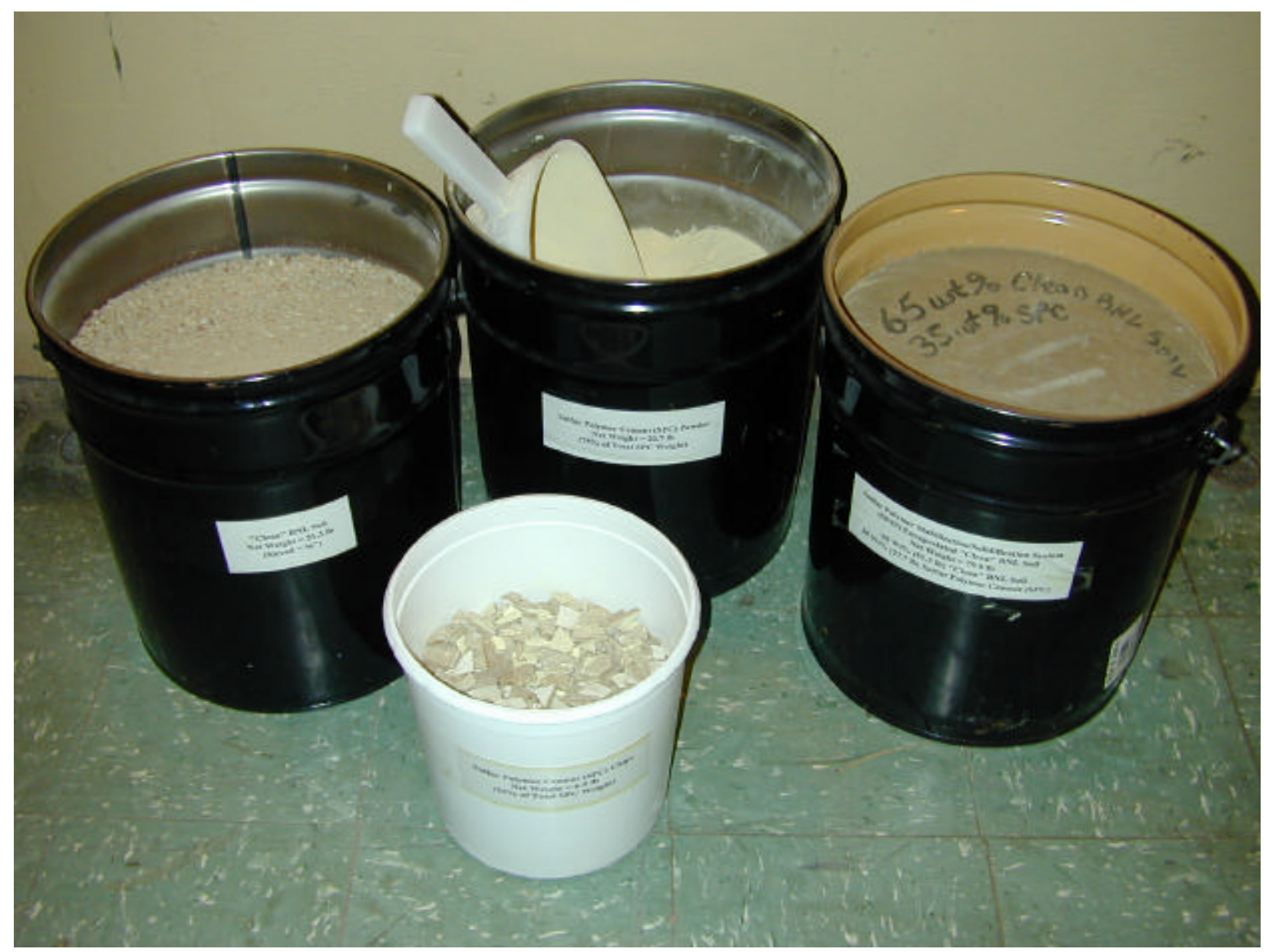

Figure 8. Volumetric Comparison of SPSS Batch Components and Final Waste Form (right).

SPSS processing of mercury-contaminated, mixed-waste soil in drum E1 was completed first. Drum E1 waste was processed as five batches. The first two batches contained 25.8 and $25.4 \mathrm{~kg}$ of as-received soil; the last three batches each contained $26.0 \mathrm{~kg}$ of as-received soil. Dry weight of soil in each batch was calculated based on moisture content of individual buckets processed. For a batch composition of $60 \mathrm{wt} \%$ dry soil and $40 \mathrm{wt} \%$ SPC, total batch weight and weight of SPC required were then calculated. For these batches, only one quarter of the total SPC, in powdered form, was added to the as-received soil to chemically stabilize mercury in the waste. For a total batch weight of $40 \mathrm{~kg}$, approximately $26 \mathrm{~kg}$ of asreceived soil was processed ( $24 \mathrm{~kg}$ dry weight), with $4 \mathrm{~kg}$ and $12 \mathrm{~kg}$ of powdered and chip-form SPC, respectively. 
Treatment of the second of two 55-gallon drums (A4) containing BNL mercury-contaminated, mixed-waste soil was similarly completed, again processing approximately $40 \mathrm{~kg}$ batches. Starting with the fourth batch, however, two significant changes were made. First, the amount of powdered SPC was increased (the ratio of powdered SPC to SPC chips changed from 1:3 to 3:1) to increase the surface area of SPC available to react with mercury droplets in the soil. Also, a small amount $(0.5 \mathrm{wt} \%)$ of a proprietary ingredient was added to further enhance mercury stabilization. Seven batches of drum A4 soil were processed, the final batch containing residuals from both drums (A4 and E1). Thus, a total of 12 batches were required to complete pilot-scale treatment of the two 55-gallon drums of waste.

TCLP samples were made by remelting the $500 \mathrm{ml}$ subsample from each batch and pouring material into Teflon molds to create small pellets, approximately $8 \mathrm{~mm}(5 / 16$ ") diameter by $8 \mathrm{~mm}(5 / 16 ")$ high, which meet the size requirement of the TCLP test while maintaining the integrity of the encapsulated product. Pelletized samples of the E-drum process batches were composited into a single $400 \mathrm{~g}$ sample (approximately $80 \mathrm{~g}$ from each of 5 batches). Similarly, a $400 \mathrm{~g}$ composite of A-drum process batches was created (approximately $60 \mathrm{~g}$ from each of 7 batches). TCLP tests were done at BNL in accordance with EPA SW-846.3-3, Method 1311. All tests were conducted using extraction fluid \#1 (pH 4.93" 0.05). Filtered, acidified leach aliquots for individual batch samples and composite samples were shipped to Severn Trent Laboratories (Whippany, NJ) for analysis. Composite pellet samples of the A4 and E1 soils were also sent for total mercury analysis.

Mercury analysis results for individual process batches and composite drum samples are summarized in Table 5. With exception of the E1 composite sample, the data indicate a significant decrease in mercury leachability compared with untreated soils (208 and $914 \mu \mathrm{g} / \mathrm{L}$, for drums E1 and A4, respectively). Considering the TCLP concentrations for drums E1-1 through E1-5 varied between $<0.4$ and $30 \mu \mathrm{g} / \mathrm{L}$, data for the E1 composite is considered anomalous. Significant improvements were attained processing Drum A4 following optimization of the formulation, resulting in leaching well below the more stringent Universal Treatment Standard levels for $\mathrm{Hg}$ of $25 \mu \mathrm{g} / \mathrm{L}$.

Table 5. TCLP Results for SPSS Treated Mercury-Contaminated, Mixed-Waste Soils.

\begin{tabular}{|l|c|c|}
\hline SPSS Batch ID & TCLP-Hg $(\mu \mathrm{g} / \mathbf{L})$ & Total Hg $(\mathbf{m g} / \mathbf{k g})$ \\
\hline E1-1 & 7.4 & \\
\hline E1-2 & 9.4 & \\
\hline E1-3 & 33 & \\
\hline E1-4 & $<0.40$ & \\
\hline E1-5 & 30 & 110 \\
\hline E1 SPSS Composite* & 147 & 4190 \\
\hline E1 Untreated Soil & 208 & \\
\hline A4-1 & 0.50 & \\
\hline A4-2 & 3.0 & \\
\hline
\end{tabular}




\begin{tabular}{|l|c|c|}
\hline A4 Composite** & 0.50 & 67.9 \\
\hline A4 Untreated Soil & 914 & 5570 \\
\hline
\end{tabular}

* Composite sample containing equal weights of batches E1-1 through E1-5.

** Composite sample containing equal weights of batches A4-1 through A4-7. Batches A4-4 through A4-7 contained $0.5 \mathrm{wt} \%$ of proprietary additive.

Mass balance between SPSS processed and unprocessed mixed-waste soil was performed to confirm that mercury contamination in the soil was indeed stabilized in the final waste form. Volume and concentration of off gas liquids, as well as weight and concentration of the carbon trap, were determined so that the amount of mercury volatilized during processing could be calculated. Representative samples were taken from each of the components of the off gas system (liquid condensate, cryogenic trap, and carbon filter) and analyzed for total mercury. For $310 \mathrm{~kg}$ of E1 and A4 soil processed, as shown in Table 6, only $0.3 \%$ of the $\mathrm{Hg}$ processed was captured in the off gas, resulting in a capture efficiency of $99.7 \%$. Approximately $90 \%$ of the moisture was accounted for in the chiller and cryogenic traps.

Table 6. Mass Balance of Condensates for SPSS Treated A4 and E1 Waste Streams.

\begin{tabular}{|l|c|c|c|}
\hline & Processed Soil Wt. (kg) & Moisture Wt. (kg) & Hg Wt. (g) \\
\hline E1 Process Runs & 154.36 & 10.58 & 679.75 \\
\hline A4 Process Runs & 155.94 & 7.94 & 868.59 \\
\hline Total Moisture + Hg Processed & 310.30 & 18.51 & 1548.33 \\
\hline & & & \\
\hline & Condensate Vol. (L) & Hg Conc. (mg/L) & Hg Wt. (g) \\
\hline Chiller Trap (E1) & 8.74 & 165 & 1.44 \\
\hline Cryogenic Trap (E1) & 0.74 & 676 & 0.50 \\
\hline Chiller Trap (A4) & 6.52 & 428 & 2.79 \\
\hline Cryogenic Trap (A4) & 0.54 & 420 & 0.23 \\
\hline & & & $\mathrm{Hg} \mathrm{Wt.} \mathrm{(g)}$ \\
\hline & Carbon Wt. (kg) & Hg Conc. (mg/kg) & 0.09 \\
\hline Carbon Trap (E1+A4) & 1.69 & 52.6 & \\
\hline & & & 5.054 \\
\hline Total Moisture+Hg Trapped & 16.55 & & $\mathbf{0 . 3}$ \\
\hline \% Moisture + Hg Trapped & $\mathbf{8 9 . 4}$ & & \\
\hline
\end{tabular}

\subsection{Liquid Mercury Mixed Waste}

Although the elemental mercury waste was much more dense than the soil waste, total weights of SPSS/liquid mercury process batches were kept approximately the same as for mercury-contaminated soil waste. Total batch volumes decreased only slightly, however, due to the increased volume of SPC used (all SPC was in powder form for these batches); reduced batch volumes were desired to enhance mixing action during the reaction phase. Bench-scale formulations were prepared with three levels of additive, 1,2, and 3 wt $\%$, to confirm that treated waste would pass TCLP. At a waste loading of $33.3 \mathrm{wt} \%$ elemental mercury, 
all samples were indeed well below EPA regulatory limits. To ensure optimal leaching results, 2 wt $\%$ additive was used for SPSS treatment of liquid mercury process batches. The $62.0 \mathrm{~kg}(136.7 \mathrm{lb})$ total inventory of liquid mercury waste was treated by dividing it into five $11.3 \mathrm{~kg}(25.0 \mathrm{lb})$ portions, with a sixth batch containing the remaining $5.4 \mathrm{~kg}(12.0 \mathrm{lb})$. Total batch weights for elemental mercury process runs were $34.0 \mathrm{~kg}(75 \mathrm{lb})$, thus a typical batch consisted of $11.3 \mathrm{~kg}(25.0 \mathrm{lb})$ of mercury, $0.7 \mathrm{~kg}(1.5 \mathrm{lb}) \mathrm{of}$ additive, and $22.0 \mathrm{~kg}(48.5 \mathrm{lb})$ of powdered SPC.

A procedure similar to that used for A-drum processing was used, with exceptions that the total mass of powdered SPC was added initially and the liquid mercury waste was added in small, approximately $20 \mathrm{ml}$ additions. To enhance dispersion of the liquid mercury, the waste was added while the screw was rotating, adding the liquid just prior to the advancing screw with each orbital rotation. With large and rapid addition of the liquid waste to the powder SPC, the dense liquid readily migrated and pooled at the bottom of the cone mixer, out of reach of the mixer screw, and therefore not agitated and reacted with the powder. After addition of the liquid mercury, the ball valve at the bottom of the mixer was cracked open to catch any pooled waste, whereupon it was re-introduced to the vessel. This process was repeated until there was no pooled mercury present at the base.

Upon completion of mixing ( $>4$ hours), the powder changed in color from bright yellow to dark grey/black in color, indicating that the reaction to mercuric sulfide had occurred. The vessel temperature was raised directly to the melt temperature, as no moisture was present in this waste. Sample volume of the molten product was approximately 4-gallons. Archive samples of all process batches were collected, as previously described. For two batches, EM-5 and 6, samples were collected to determine whether stratification of the encapsulated SPSS material had occurred due to the high density of the amalgamated mercury phase. Approximately $1 / 3$ of the batch was poured, a sample collected (labeled "bottom"), the second third of the batch poured (labeled "middle") and the final third poured (labeled "top").

Pellet samples were prepared from all batch archive samples for subsequent TCLP extraction. A certified laboratory completed TCLP testing. TCLP data, shown in Table 7, were all well below UTS limits for Hg $(25 \mu \mathrm{g} / \mathrm{L})$.

Table 7. TCLP Results for SPSS Treated Elemental Mercury.

\begin{tabular}{|c|c|}
\hline SPSS Batch ID & TCLP-Hg $(\mu \mathbf{g} / \mathbf{L})$ \\
\hline EM-1 & $<0.40$ \\
\hline EM-2 & $<0.40$ \\
\hline EM-3 & $<0.40$ \\
\hline EM-4 & 0.70 \\
\hline EM-5T (top) & 9.3 \\
\hline EM-5M (middle) & 1.2 \\
\hline EM-5B (bottom) & $<0.40$ \\
\hline
\end{tabular}




\begin{tabular}{|l|l|}
\hline EM-6C composite* & 4.9 \\
\hline
\end{tabular}

* Composite sample containing equal weights of top, middle, and bottom grab samples.

\section{SUMMARY AND CONCLUSIONS}

A large volume of mercury-contaminated mixed-waste soil requiring treatment was generated at BNL as a result of recent environmental restoration activities. Current EPA treatment standards for mixed wastes containing $>260 \mathrm{mg} / \mathrm{L}$ mercury (retort) are not appropriate since the mercury cannot be recycled and secondary wastes requiring further treatment are produced. Thus, direct stabilization for disposal of these high concentration mercury-mixed wastes is sought, and DOE MWFA supported a comparison of several treatment options. Pilot-scale treatment using SPSS resulted in successful treatment of the soil at a waste loading of $60 \mathrm{wt} \%$ soil, with no increase in waste volume. Higher waste loadings may be possible but due to viscosity limitations of the mixture, would require engineering modifications of the process equipment. The waste form product easily meets both existing TCLP and more stringent UTS leaching criteria. Results of an Accelerated Leach Test (ASTM C-1308) for mixed-waste elemental mercury treated by the BNL Sulfur Polymer Stabilization/Solidification (SPSS) process indicate diffusion is the predominant leaching mechanism. Extremely low leach rates were observed with diffusion coefficients ranging between $10^{-17}$ and $10^{-18}$ (11 -12 orders of magnitude better than minimum leach rates recommended by NRC for radioactive contaminants).

Plans to demonstrate at full-scale and commercially license the SPSS technology are currently being discussed.

\section{ACKNOWLEDGMENTS}

The work to setup and demonstrate the SPSS process on mercury-contaminated, mixed-waste soils was funded by the U.S. Department of Energy Office of Science and Technology, Mixed Waste Focus Area (DOE MWFA). Processing of liquid, mercury-mixed waste at Brookhaven National Laboratory was performed under contract with the BNL Office of Environmental Restoration (OER).

The authors are thankful for the contributions of our co-workers at BNL, namely Drs. Mark Fuhrmann and Dan Melamed, for consultation during this process scale-up, and Maryanne Sapanara and Cassia DeTello, for their experimental and analytical support. Greg Hulet and Jay Roach of the DOE MWFA, managed and championed this work. Jim Brower, Gail Penny, and Andy Lockwood (OER) were generously supportive in processing actual waste at BNL. 


\section{REFERENCES}

1. Colombo, P., Kalb, P.D., and Heiser, J. H, "Process for the Encapsulation and Stabilization of Radioactive, Hazardous and Mixed Wastes,” U.S. Patent 5,678,234, October 14, 1997.

2. Kalb, P.D., Heiser, J.H., Pietrzak, R., and Colombo, P., "Durability of Incinerator Ash Waste Encapsulated in Modified Sulfur Cement," Presented at the 1991 Incineration Conference: Thermal Treatment of Radioactive, Hazardous, Chemical, Mixed, and Medical Wastes, Knoxville, TN, May 1991.

3. Kalb, P.D., Heiser, J.H., and Colombo, P., "Modified Sulfur Cement Encapsulation of Mixed Waste Contaminated Incinerator Fly Ash,” Waste Management, Vol. 11, No. 3, pp. 147-153, Pergamon Press, 1991.

4. Kalb, P.D., Melamed, D., Fuhrmann, M., Adams, J.W., Sapanara, M., and DeTello C., "Sulfur Polymer Stabilization/Solidification of Elemental Mercury Mixed Waste," Presented at $19^{\text {th }}$ U.S. Department of Energy Low-Level Radioactive Waste Management Conference, Salt Lake City, UT, November 1998.

5. MWFA, "Mercury Amalgamation: Mixed Waste Focus Area Technology Development Requirements Document,” INEL/EXT-97-00314, LMITCO, Idaho Fall, ID, March 1997.

6. US EPA, “Land Disposal Restrictions, Subpart D- Treatment Standards, ” 40 CFR 268.40, Code of Federal Regulations, Office of the Federal Register National Archives and Records Administration, 1996.

7. Gorin, A.H., J. H. Leckey and L.E. Nulf, "Final Disposal Options for Mercury/Uranium Mixed Wastes From The Oak Ridge Reservation”, Y/DZ-1106, August 1994.

8. Colombo, P., Kalb, P.D., Heiser, J. H. "Process for the Encapsulation and Stabilization of Radioactive, Hazardous and Mixed Wastes.” U.S. Patent 5,678,234, October 14, 1997.

9. Kalb, P.D., J.H. Heiser, R. Pietrzak, and P. Colombo, "Durability of Incinerator Ash Waste Encapsulated in Modified Sulfur Cement," Presented at the 1991 Incineration Conference: Thermal Treatment of Radioactive, Hazardous, Chemical, Mixed, and Medical Wastes, Knoxville, TN, May 1991.

10. Kalb, P.D., J.H. Heiser, and P. Colombo, "Modified Sulfur Cement Encapsulation of Mixed Waste Contaminated Incinerator Fly Ash,” Waste Management, Vol. 11, No. 3, pp. 147-153, Pergamon Press, 1991.

11. US EPA, "Storage, Treatment, Transportation and Disposal of Mixed Waste; Proposed Rule," 
US EPA, 40CFR Part 266, Federal Register: November 19, 1999 (Volume 64, Number 223), Page 63463-63501. 